\title{
NOTES ON THE OLD PERSIAN SIGNS*
}

\author{
by
}

GERNOT L. WINDFUHR

The University of Michigan

Achaemenian Persia is the last great empire of the Ancient Near East. For its monumental inscriptions a new script was developed, the last cuneiform of the Ancient Near East. ${ }^{1}$

Some scholars still doubt that the signs were invented, in spite of the fact that the signs exhibit no relationship whatsoever with other cuneiform scripts like the Elamite, Akkadian, Hurrian, or Hittite cuneiforms. ${ }^{2}$ The majority of scholars, however, accepts the lack of paleographic relationship as evidence for the invention of the script. ${ }^{3}$ In fact, it is hard to expect that any missing link will ever be found, i.e. a script that would connect the Old Persian cuneiform with the others. ${ }^{4}$ Additional evidence for the invention of the script is offered by the present discovery that the Old Persian signs are constructed by the application of only four basic principles.

* I am highly indebted to Prof. George G. Cameron for his scholarly criticism which led to the final solution of the problem and the final form of this article. I am equally grateful for discussions with Prof. Wolfgang Lentz and Prof. Herbert $H$. Paper.

1 The better preserved Elamite version of Behistun \#70 has both: '(3) machte ich eine andersartige Schrift, (4) auf Arisch, was es vordem nicht gab," Walter Hinz, "Die Einführung der altpersischen Schrift", $Z D M G, 102$ (1952), pp. 28-38; OP $a-r a-i-y a-a$ (DB) IV: 88-92 (\#70) 'Aryan' cannot be read as a-na-i-ya-a 'another' according to G. G. Cameron's 'Rundbrief' from July 9, 1966, p. 3.

2 See e.g. the convincing beginning and inconclusive end of the article of J. Halévy, "Note sur l'origine de l'écriture perse", $J A, 8$ ème série, tome 6 (1885), pp. 480-502.

3 See discussion and literature in F. H. Weissbach, Die Keilinschriften der Achämeniden (Leipzig, 1911), p. LXV; Hinz, loc. cit.; an example of the bitterness of the fight between the two factions is documented in the amusing controversy between Herzfeld, "Das Alter der altpersischen Schrift", ZDMG, 64 (1910), pp. 63-64, Ferdinand Bork, "Nochmals das Alter der altpersischen Schrift", ib., pp. 569-580, and Weissbach, "Zur Kritik der Achämenideninschriften", ZDMG, 67 (1913), pp. 271-341.

- The only signs that are alike are OP and Akk/Elam $l$, which gives indirect evidence for a late invention of the script, see $\mathbf{H}$. H. Paper, "The Old-Persian /1/-Phoneme", $J A O S, 76,1$ (1956), pp. 24-26; on p. 25 he makes the point that "it would be difficult to imagine such names as Tigra- 'Tigris' ... occurring with $/ \mathrm{r} /$ rather than with $/ 1 /$, if the OP syllabary had been developed in pre-Achaemenid times." 
The following discussion is only concerned with the syllabary, not with the ideograms, the number signs and the word divider. The phonetic values of the signs will not be included..$^{5}$ The sole object of analysis are the 36 signs of the syllabary as graphical signs.

The 36 signs of the syllabary are composed of 2 to 5 wedges which may be vertical, horizontal, or angle-shaped. The feature 'angle' divides the signs exactly into two sets of 18 members each (table: $A+B, C+D$ ).

A sign is composed of a basic component and additional wedges.

There are 4 basic components (table: A, B, C, D):

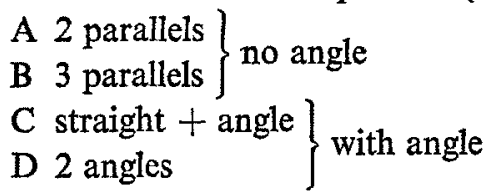

The basic components are derived from each other by adding 1 parallel: $\mathrm{A} \rightarrow \mathrm{B}$; or changing first 1 , then 2 parallels, to an angle: $A \rightarrow C \rightarrow D$. (The derivation may go in the reverse direction with exactly the same results.) ${ }^{6}$

1,2 , or 3 wedges are added to the basic components, a method by which 10 basic groups are derived (table: nos. 1-10):

\begin{tabular}{|c|c|c|c|c|c|c|c|c|c|}
\hline & & & & & TABL & & & & \\
\hline dir & ection: & L & $U$ & $R$ & $\mathbf{M}$ & & ansli & eratio & \\
\hline & 1. & $\Rightarrow$ & III & $1=$ & ii & $b a$ & $d a$ & $k a$ & $i$ \\
\hline A & 2. & $\Rightarrow 1$ & $\overline{\overline{1}}$ & $\pi-$ & $1-1$ & $l a$ & $c ̧ a$ & $c a$ & $z a$ \\
\hline & 3. & $\equiv \|$ & $\bar{\Pi}$ & $=I I I$ & $-l \equiv$ & $d i$ & $p a$ & $t a$ & $v a$ \\
\hline & 4. & $\equiv 1$ & iii & $1 \equiv$ & & $r a$ & $\bar{a}$ & $s a$ & \\
\hline B & 5. & -111 & $i^{+}$ & III- & & $m a$ & $v i$ & $t u$ & \\
\hline & 6. & $-K$ & $\mathrm{KI}$ & $K-$ & $<1$ & $j a$ & $\theta a$ & $y a$ & $k u$ \\
\hline $\mathrm{C}$ & 7. & $K=$ & $<\pi$ & $\langle I t$ & $=<$ & $m i$ & $u$ & $g a$ & $n a$ \\
\hline & 8. & $-\xi$ & $\Leftrightarrow 1$ & $\Leftrightarrow$ & $\equiv$ & $j i$ & $d u$ & $g u$ & $m u$ \\
\hline & 9. & $-\ll$ & K & $\bar{\ll}$ & & $r u$ & $f a$ & $\check{s a}$ & \\
\hline & 10. & $\ll$ & $\ll \|$ & $\Leftrightarrow<$ & & & $x a$ & $h a$ & \\
\hline
\end{tabular}

s For the tabulation and phonematization of the OP syllabary see $\mathbf{H}$. H. Paper, op. cit., p. 26, and the purely phonetic considerations by Jerzy Kurylowicz, "Zur altpersischen Schrift", Esquisses Linguistiques (Wrocław-Kraków, 1960), pp. 274-280; also the similar, though less systematic observations by Richard Lepsius, "Über das Lautsystem der Persischen Keilschrift", Abhandlungen der kgl. Akademie der Wissenschaften zu Berlin aus dem Jahre 1862 (Berlin, 1863), pp. 385-412.

- That the basic components are derivable from each other is an observation made by Dr. Wolfhard Schlosser, an interested astronomer. 
basic component additional wedges

table number
A 2 parallels
(a) 1
(b) 2
2
(c) 3
3
B 3 parallels
(a) 1 lying, or l on basic
4
(b) 1 standing $\int$ component 5
C straight + angle
(a) 1
6
(b) 2
7
(c) 3
8
D 2 angles
(a) 1
9
(b) 2
10

As in $\mathrm{Ba}$, there is only $\mathrm{l}$ additional wedge in $\mathrm{Bb}$. In comparison with the other b-groups ( $\mathrm{Ab}, \mathrm{Cb}, \mathrm{Db})$ one would expect 2 additional wedges. Instead, this single additional wedge in $\mathrm{Bb}$ is distinguished from that in $\mathrm{Ba}$ by rotation: while in $\mathrm{Ba}$ the wedge lies on the basic component, it is standing in $\mathrm{Bb}$, i.e. turned by $90^{\circ}$. The reason for this deviation is obvious: the basic component of $\mathrm{B}=3$ parallels, +2 additional wedges would be identical with the basic component of $\mathrm{A}=2$ parallels, +3 additional wedges, i.e. with the signs of Ac. Therefore, this rotation in $\mathrm{Bb}$ must be regarded as a device which is functionally equal to 2 additional wedges.

The individual members of the 10 basic groups are distinguished from each other by rotation (table: LUR) and mirroring or deviation (table: M).

Rotation is threefold: the additional wedge(s), part of the basic group, or the entire group is turned (a) to the Left, (b) Upright or on top, (c) to the Right (table: LUR, nos. 1-8); or, the threefold rotation is somewhat differently achieved by the (a) horizontal, (b) vertical, (c) on top, or inserted, position of the additional wedge(s) (table: LUR, nos. 9-10). Functionally, both types of rotation seem to be equal.

Three signs are mirror images of the basic component or groups of $\mathrm{C}$ a-c, so that each of the groups 6-8 has a Mirrored fourth member, besides the 3 rotated members (table: $M$ 6-8):

M6: $k u=$ angle + vertical, is the mirror image of the basic component of $\mathrm{C}$ which is vertical + angle;

M7: $n a=2$ horizontals + angle, is the mirror image of the basic group of $\mathrm{Cb}$ which is angle +2 wedges (which may be horizontal or vertical);

M8: $m u=3$ horizontals + angle + horizontal, is the mirror image of 
the basic group of $\mathrm{Cc}$ which is angle +3 horizontals, with the addition of 1 horizontal so that $m u$ appears as the exact mirror image of $j i$.

Mirroring the signs without an angle would be non-distinctive, since this results in identical signs, e.g. mirroring $d a$ would give $d a$ etc. This observation must have been the reason why, instead of mirroring, different distinctions were made which are subsumed here under the term deviation. Three signs are deviations of the basic component or groups of A a-c, so that each of the groups 1-3 has a fourth deviated member, besides the 3 rotated members (table: M 1-3):

M1: $i$, where the additional wedge of Aa is divided into two small wedges on top of the basic parallels;

M2: $z a$, where the two additional wedges of $A b$ are inserted between the basic parallels;

M3: $v a$, where one of the basic parallels of $\mathrm{Ac}$ is turned by $90^{\circ}$.

For the reasons mentioned above, deviation must be functionally equal to mirroring.

There are no fourth signs for the groups 4-5 and 9-10; instead, mirroring and deviation are inherent features of these groups: deviation is the feature that distinguishes the entire group 4 from 5 , as demonstrated above; the deviation is: standing additional wedge $(\mathrm{Bb})$ vs. lying wedge (Ba), i.e. turning by $90^{\circ}$ (table: 4,5 ); similarly, mirroring is the feature that distinguishes the groups 9 and 10: the sequence of the additional wedges + basic component is reversed; while in 9 the additional wedges are on the left, they are on the right in 10 . As mentioned above, the other distinguishing feature of these two groups is 1 vs. 2 additional wedges (table: 9,10 ).

To summarize: the basic principles of sign composition are:

1. derivation of 4 basic components;

2. addition of $1,2,3$ wedges;

3. threefold rotation;

4. mirroring.

The functionally equal differentiations were discussed above.

By the application of these four principles, the signs are divided into sets of $18,12,10,6,4,3$ members: there are 18 signs with an angle, 18 signs without one; 12 signs with 1 angle, 6 signs with $2 ; 12$ signs with the basic component of 2 parallels, 6 with the basic component of 3 parallels; 10 signs are turned left or horizontal, 10 signs upright, 10 signs 
turned right, or the additional wedge is on top or inserted; there are 6 sets with 4 members each; finally, there are 12 sets with 3 members each (the 6 mirrored and deviated signs constitute 2 sets of their own).

This system of sets is completely symmetrical: each set, subset, and sign with an angle corresponds with a set, subset, and sign without an angle:

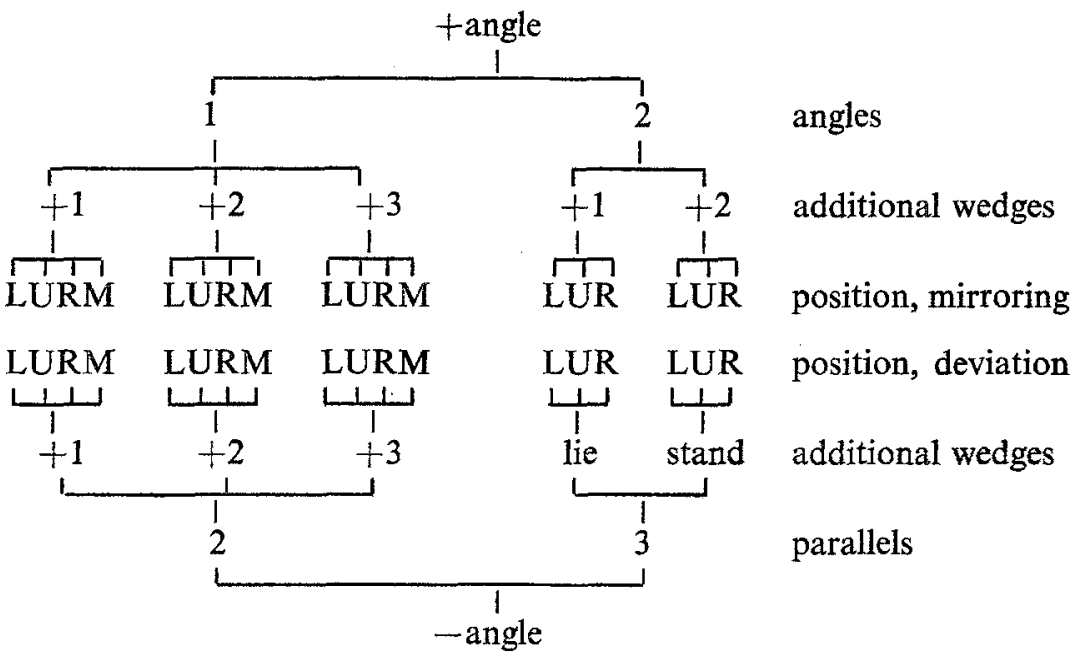

Elementary estimates of probability exclude the possibility that such a system is naturally or historically developed. ${ }^{7}$ Those who believe in a natural origin must believe in some magic that counted, arranged, and shaped the wedges so that this kind of symmetry evolved. However, one cannot exclude the possibility that this system is the result of stylistic simplification. But then it may have been a Magus - but not nature which selected just these principles. ${ }^{8}$ But why?

7 Dr. Schlosser calculated that possibility as less probable than 1:50,000.

8 The number 36 and its division into equal sets suggest as basic figure a circle and/or a hexagon. It is not impossible that the subsets of $2 \times 12$ signs represent the signs of the zodiac, and the $2 \times 3$ subsets of 4 members may indicate the 3 parts of the year; and further, that the rotation and mirroring stands for the first, second, third, and fourth (changing-over) month, while the sets of 6 may represent the 6 festivals of the year. This analogy could be drawn further. I leave it to the reader to go on or disapprove of this. With regard to the problem of the phonetic-graphical relation, there is the remote possibility that each of the sets of 3 members represents a word, so that the whole arrangement could be a merk-spruch (cf. ba-da-ka=bandaka? or $m a$ vi $t u=m \tilde{a}$ vayatu?). 